\title{
Frequency and Influencing Factors of Rubber Dam Usage in Tianjin: A Questionnaire Survey
}

\author{
Huiru Zou, Yanni Li, Xiaoli Lian, Yan Yan, Xiaohua Dai, and Guanhua Wang \\ Research Center of Tianjin Stomatological Hospital, 75 Dagu Road, Heping District, Tianjin 300041, China \\ Correspondence should be addressed to Huiru Zou; zouhuiru@163.com
}

Received 6 April 2016; Accepted 22 May 2016

Academic Editor: Louis M. Lin

Copyright ( 2016 Huiru Zou et al. This is an open access article distributed under the Creative Commons Attribution License, which permits unrestricted use, distribution, and reproduction in any medium, provided the original work is properly cited.

\begin{abstract}
Objective. To investigate the frequency and influencing factors of rubber dam usage for endodontic procedures among general dentistry practitioners and specialized practitioners (endodontist) in Tianjin. Methods. Three hundred questionnaires were distributed among practitioners from 3 different types of medical institutions in Tianjin. Data were collected and analysed using Chi-square tests. Results. There were $63.3 \%$ of respondents who have used rubber dam (response rate $82.7 \%$, valid response rate $76.3 \%$ ). However, only $0.4 \%$ and $3.1 \%$ of them recognized using rubber dam "every time" during caries direct restoration and root canal therapy, respectively. There was no significant difference in rubber dam usage between male and female practitioners. Among the respondents, practitioners with working experience between 5 and 10 years showed the highest usage rate (76.3\%), while practitioners working more than 20 years showed the lowest (53.2\%). The endodontists gained the highest and the most frequent usage rate and the best rubber dam technique mastering skills. Practitioners working in those stomatological departments of general hospitals showed the lowest rubber dam usage rate. Conclusions. The prevalence of rubber dam usage in Tianjin city is still low. The practitioner's gender, years of professional experience, general or specialized field, and the type of dental setting they work for are the factors that need to be considered during making policy and executing training.
\end{abstract}

\section{Introduction}

Since being introduced by Dr. Barnum in the 1860s, rubber dam isolation technique has gradually gained recognition as an essential technique in the process of dental treatments. The benefits of rubber dam are well known, which can effectively protect patients and doctors and provide a more professional, safe, and comfortable medical experience. However, various prevalences of rubber dam usage have been reported from different countries [1-6]. In China, little data on utilization rate is available. This study conducted a questionnaire survey of 300 dentists from 18 medical institutional dental settings in Tianjin, in order to determine the overall attitude of dentists towards rubber dam application, explore possible influencing factors such as the practitioner's gender, years of professional experience, general or specialized field, and the type of medical institutional dental settings they work for, and hopefully make some contribution in policies development on how to promote the rubber dam technique usage in dental practice in China.

\section{Materials and Methods}

2.1. Dentists Recruited. Three hundred general dentists and endodontists from 2 stomatological hospitals, 11 stomatological departments of general hospitals, and 5 private hospitals were selected in this questionnaire survey. Inclusive criteria were as follows: all employed practitioners from above institutions, including graduate intern. Undergraduate and college students were excluded from this study.

2.2. Survey Content. The questionnaire consisted of 30 questions concerning different aspects of rubber dam usage, such as (1) the basic information regarding the practitioner's gender, years of professional experience, general or specialized field, and the type of medical institutional settings they work for, (2) rubber dam awareness, source of knowledge gained for rubber dam usage, and prevalence in caries filling and root canal treatment application, and (3) the time required for the clinical installation of rubber dam and problems occurring during rubber dam usage. This survey divided the mastery 
degree of rubber dam technique into 4 levels as $0,1,2$, and 3. Level 0 means totally having no knowledge of rubber dam technique. Level 1 means having some knowledge of rubber dam technique, but having no practical experience. Level 2 means knowing some and handling easy situations but not dealing with complex cases. Level 3 means fully mastering rubber dam technique and handling any situations without problem. Practitioners were asked to make selfassessment of the extent of their rubber dam technique skills. This study mainly analysed the possible effects of influencing factors such as the practitioner's gender, years of professional experience, field and the type of medical institutions on the mastery degree, and prevalence of rubber dam usage.

2.3. Survey Method and Statistical Analysis. All questions had 2 or more different choices. Respondents were informed to choose one or more suitable answers. Three persons were entrusted for handling out and collecting the questionnaires. Questionnaire with unanswered questions were treated as invalid questionnaire. All data collected from the questionnaire survey were entered into Microsoft Excel using a double entry method. SPSS17.0 statistical software was used for statistical analysis. Frequencies and percentage distributions were analysed using Chi-square test to investigate the influence of gender, years of professional experience, and field and type of medical institutions on rubber dam usage. The chosen level of statistical significance was set at $P<0.05$.

\section{Results}

Eighteen medical institutional dental settings in Tianjin City were selected in this questionnaire survey study. Three hundred surveys were distributed; a total of 248 questionnaires were collected back (the questionnaire recovery rate was $82.7 \%$ ); and 229 of the 248 returned surveys are valid questionnaires (the valid response rate is $76.3 \%$ ). The distribution of the medical institution and the recovery of the respondents in the survey are shown in Figure 1. Altogether, 102 (44.5\%) were males, while 127 (55.5\%) were females. The working experience of respondents was shown in Figure 2. The field (general or specialized) of practice scope of respondents who engaged in dentistry was shown in Figure 3. The distribution of the type of medical institutions where respondents work was shown in Figure 4.

There were $63.3 \%$ of respondents having used rubber dam. However, only $0.4 \%$ and $3.1 \%$ of practitioners (general dentists versus endodontists) recognized that they always use rubber dam during dental caries direct restoration and root canal therapy, respectively; $45.4 \%$ and $39.7 \%$ of them "never" use rubber dam during these procedures, respectively. $14 \%$ of respondents were of "Level 0 ," $40.6 \%$ of "Level 1," and $34.9 \%$ of "Level 2" in their self-assessment of rubber dam technique mastery degree; only $10.5 \%$ of respondents marked themselves as Level 3.

Table 1 showed that $68.6 \%$ of male respondents and $59.1 \%$ of female respondents have used rubber dam. There was no significant difference between different genders $(P>$ 0.05). Refined to the caries filling treatment and root canal
TABLE 1: Respondents' gender and rubber dam usage.

\begin{tabular}{lccc}
\hline & Total & Male & Female \\
\hline Have used rubber dam & & & \\
$\quad$ Yes & $145(63.3 \%)$ & $70(68.6 \%)$ & $75(59.1 \%)$ \\
No & $84(36.7 \%)$ & $32(31.4 \%)$ & $52(40.9 \%)$ \\
\hline Use rubber dam in caries & & & \\
filling & $104(45.4 \%)$ & $43(42.2 \%)$ & $61(48.0 \%)$ \\
Never use & $87(38.0 \%)$ & $41(40.2 \%)$ & $46(36.2 \%)$ \\
Occasionally use & $37(16.2 \%)$ & $17(16.7 \%)$ & $20(15.7 \%)$ \\
Often use & $1(0.4 \%)$ & $1(1.0 \%)$ & $0(0.0 \%)$ \\
Always use & & &
\end{tabular}

Use rubber dam in root

canal treatment

\begin{tabular}{lccc} 
Never use & $91(39.7 \%)$ & $37(36.3 \%)$ & $54(42.5 \%)$ \\
Occasionally use & $77(33.6 \%)$ & $40(39.2 \%)$ & $37(29.1 \%)$ \\
Often use & $58(25.3 \%)$ & $22(21.6 \%)$ & $36(28.3 \%)$ \\
Always use & $7(3.1 \%)$ & $3(2.9 \%)$ & $4(3.1 \%)$ \\
\hline
\end{tabular}

Mastery degree of rubber

dam usage

$\begin{array}{llll}\text { Level } 0 & 32(14.0 \%) & 12(11.8 \%) & 20(15.7 \%)\end{array}$

Level $1 \quad 93(40.6 \%) \quad 46(45.1 \%) \quad 47(37.0 \%)$

Level $2 \quad 80(34.9 \%) \quad 33(32.4 \%) \quad 47(37.0 \%)$

\begin{tabular}{cccc} 
Level 3 & $24(10.5 \%)$ & $11(10.8 \%)$ & $13(10.2 \%)$ \\
\hline Total & 229 & 102 & 127
\end{tabular}

treatment, there was also no significant difference of rubber dam usage $(P>0.05)$.

$76.3 \%$ of 5 years $<$ work $\leq 10$ years respondents have used rubber dam which was the highest rate, while work $>20$ years respondents showed the lowest (53.2\%). But there were no significant differences $(P>0.05)$ (Table 2$)$.

Tables 3 and 4 showed that there were significant differences among general or specialized fields and the type of medical institutions in rubber dam usage rates $(P<0.01)$. The endodontic specialists gained the highest and the most frequently usage rate and the best rubber dam technique mastering skills. Respondents' self-assessment results also showed significant differences among different medical institutions $(P<0.01)$.

\section{Discussion}

Rubber dam is considered an ideal device for tooth isolation. The use of rubber dam provides a significantly higher success rate during restorative procedures and root canal treatment [7]. In recent years, the application of rubber dam isolation technique in dental treatment is becoming more and more widely spread. However, the level and development of its usage around the world are still uneven. A survey investigating general practitioners in the United States showed that $60 \%$ respondents always use rubber dam, 16\% usually use it, $13 \%$ sometimes use it, and $11 \%$ never use it [6]. After surveying 1716 eligible general dentists, Lawson et al. reported that 697 (47\%) always use rubber dam, while this percentage varied 


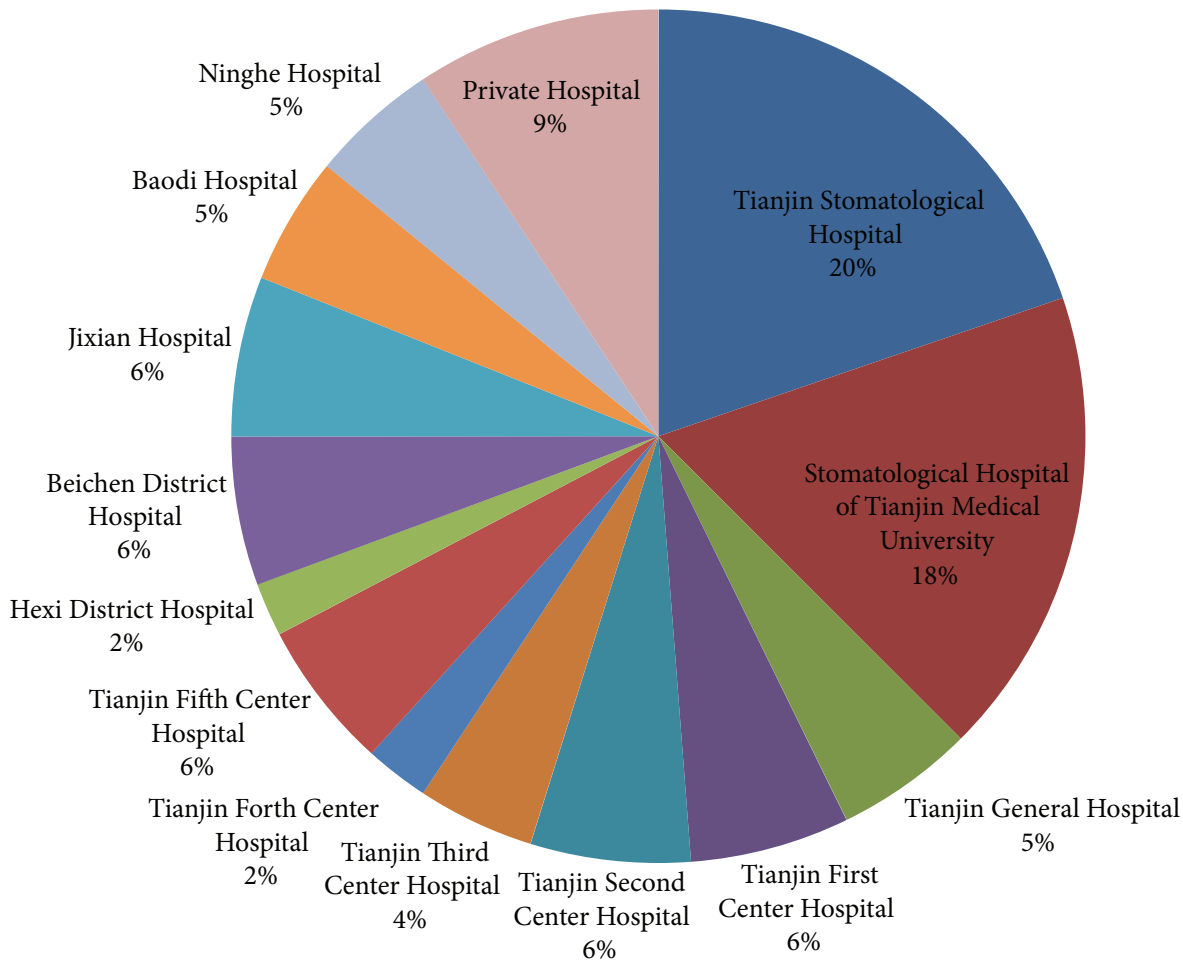

FIGURE 1: The distribution of medical institutions and the recovery of respondents.

TABLE 2: Respondents' years of working experience and rubber dam usage.

\begin{tabular}{|c|c|c|c|c|c|c|c|}
\hline & Total & Internship & Work $\leq 1$ year & $\begin{array}{c}1 \text { year }<\text { work } \\
\leq 5 \text { years }\end{array}$ & $\begin{array}{c}5 \text { years }<\text { work } \\
\leq 10 \text { years }\end{array}$ & $\begin{array}{c}10 \text { years }<\text { work } \\
\leq 20 \text { years }\end{array}$ & $\begin{array}{c}\text { Work }>20 \\
\text { years }\end{array}$ \\
\hline \multicolumn{8}{|l|}{$\begin{array}{l}\text { Have used rubber } \\
\text { dam }\end{array}$} \\
\hline Yes & $145(63.3 \%)$ & $10(55.6 \%)$ & $8(72.7 \%)$ & $26(57.8 \%)$ & $45(76.3 \%)$ & $31(63.3 \%)$ & $25(53.2 \%)$ \\
\hline No & $84(36.7 \%)$ & $8(44.4 \%)$ & $3(27.3 \%)$ & $19(42.2 \%)$ & $14(23.7 \%)$ & $18(36.7 \%)$ & $22(46.8 \%)$ \\
\hline \multicolumn{8}{|l|}{$\begin{array}{l}\text { Use rubber dam in } \\
\text { caries filling }\end{array}$} \\
\hline Never use & $104(45.4 \%)$ & $10(55.6 \%)$ & $3(27.3 \%)$ & $22(48.9 \%)$ & $19(32.2 \%)$ & $24(49.0 \%)$ & $26(55.3 \%)$ \\
\hline Occasionally use & $86(37.6 \%)$ & $8(44.4 \%)$ & $7(63.6 \%)$ & $19(42.9 \%)$ & $25(42.4 \%)$ & $15(30.6 \%)$ & $12(25.5 \%)$ \\
\hline Often use & $38(16.6 \%)$ & $0(0.0 \%)$ & $1(9.1 \%)$ & $4(8.9 \%)$ & $15(25.4 \%)$ & $10(20.1 \%)$ & $8(17.0 \%)$ \\
\hline Always use & $1(0.4 \%)$ & $0(0.0 \%)$ & $0(0.0 \%)$ & $0(0.0 \%)$ & $0(0.0 \%)$ & $0(0.0 \%)$ & $1(2.1 \%)$ \\
\hline \multicolumn{8}{|l|}{$\begin{array}{l}\text { Use rubber dam in } \\
\text { root canal treatment }\end{array}$} \\
\hline Never use & $91(39.7 \%)$ & $9(50.0 \%)$ & $4(36.4 \%)$ & $18(40.0 \%)$ & $14(23.7 \%)$ & $23(46.9 \%)$ & $23(48.9 \%)$ \\
\hline Occasionally use & $77(33.6 \%)$ & $8(44.4 \%)$ & $5(45.5 \%)$ & $17(37.8 \%)$ & $20(33.9 \%)$ & $13(26.5 \%)$ & $14(29.8 \%)$ \\
\hline Often use & $54(23.6 \%)$ & $1(5.6 \%)$ & $2(18.2 \%)$ & $10(22.2 \%)$ & $22(37.3 \%)$ & $11(22.4 \%)$ & $8(17.0 \%)$ \\
\hline Always use & $7(3.1 \%)$ & $0(0.0 \%)$ & $0(0.0 \%)$ & $0(0.0 \%)$ & $3(5.1 \%)$ & $2(4.1 \%)$ & $2(4.3 \%)$ \\
\hline \multicolumn{8}{|l|}{$\begin{array}{l}\text { Mastery degree of } \\
\text { rubber dam usage }\end{array}$} \\
\hline Level 0 & $32(14.0 \%)$ & $2(11.1 \%)$ & $1(9.1 \%)$ & $6(13.3 \%)$ & $7(11.9 \%)$ & $5(10.2 \%)$ & $11(23.4 \%)$ \\
\hline Level 1 & $93(40.6 \%)$ & $13(72.2 \%)$ & $8(72.7 \%)$ & $18(40.0 \%)$ & $14(23.7 \%)$ & $22(444.9 \%)$ & $18(38.3 \%)$ \\
\hline Level 2 & 80 (34.9\%) & $2(11.1 \%)$ & $2(18.2 \%)$ & $17(37.8 \%)$ & $29(49.2 \%)$ & $16(32.7 \%)$ & $14(29.8 \%)$ \\
\hline Level 3 & $24(10.5 \%)$ & $1(5.6 \%)$ & $0(0.0 \%)$ & $4(8.9 \%)$ & $9(15.3 \%)$ & $6(12.2 \%)$ & $4(8.5 \%)$ \\
\hline Total & 229 & 18 & 11 & 45 & 59 & 49 & 47 \\
\hline
\end{tabular}


TABLE 3: Respondents' clinical specialty and rubber dam usage.

\begin{tabular}{|c|c|c|c|c|}
\hline & \multirow{2}{*}{ Total } & \multirow{2}{*}{ General } & \multicolumn{2}{|c|}{ Specialized } \\
\hline & & & Endodontic & Nonendodontic \\
\hline \multicolumn{5}{|c|}{ Have used rubber dam } \\
\hline Yes & $145(63.3 \%)$ & $75(56.4 \%)$ & $63(81.8 \%)$ & $7(36.8 \%)$ \\
\hline No & $84(36.7 \%)$ & $58(43.6 \%)$ & $14(18.2 \%)$ & $12(63.2 \%)$ \\
\hline \multicolumn{5}{|c|}{ Use rubber dam in caries filling } \\
\hline Never use & $104(45.4 \%)$ & $75(54.1 \%)$ & $17(22.1 \%)$ & $15(78.9 \%)$ \\
\hline Occasionally use & $86(37.6 \%)$ & $49(36.8 \%)$ & $33(42.9 \%)$ & $4(21.1 \%)$ \\
\hline Often use & $38(16.6 \%)$ & $11(8.3 \%)$ & $27(35.1 \%)$ & $0(0.0 \%)$ \\
\hline Always use & $1(0.4 \%)$ & $1(0.8 \%)$ & $0(0.0 \%)$ & $0(0.0 \%)$ \\
\hline \multicolumn{5}{|c|}{ Use rubber dam in root canal treatment } \\
\hline Never use & $91(39.7 \%)$ & $64(48.1 \%)$ & $13(16.9 \%)$ & $14(73.7 \%)$ \\
\hline Occasionally use & $77(33.6 \%)$ & $49(36.8 \%)$ & $23(29.9 \%)$ & $5(26.3 \%)$ \\
\hline Often use & $54(23.6 \%)$ & $18(13.5 \%)$ & $36(46.8 \%)$ & $0(0.0 \%)$ \\
\hline Always use & $7(3.1 \%)$ & $2(1.5 \%)$ & $5(6.5 \%)$ & $0(0.0 \%)$ \\
\hline \multicolumn{5}{|c|}{ Mastery degree of rubber dam usage } \\
\hline Level 0 & $32(14.0 \%)$ & $23(17.3 \%)$ & $4(5.2 \%)$ & $5(26.3 \%)$ \\
\hline Level 1 & $93(40.6 \%)$ & $70(52.6 \%)$ & $13(16.9 \%)$ & $10(52.6 \%)$ \\
\hline Level 2 & $80(34.9 \%)$ & $34(25.6 \%)$ & $42(54.5 \%)$ & $4(21.1 \%)$ \\
\hline Level 3 & $24(10.5 \%)$ & $6(4.5 \%)$ & $18(23.4 \%)$ & $0(0.0 \%)$ \\
\hline Total & 229 & 133 & 77 & 19 \\
\hline
\end{tabular}

TABLE 4: The type of medical institutions where respondents work and rubber dam usage.

\begin{tabular}{|c|c|c|c|c|}
\hline & Total & Specialized hospital & General hospital & Private hospital \\
\hline \multicolumn{5}{|c|}{ Have used rubber dam } \\
\hline Yes & $145(63.3 \%)$ & $75(80.6 \%)$ & $58(47.9 \%)$ & $12(80.0 \%)$ \\
\hline No & $84(36.7 \%)$ & $18(19.4 \%)$ & $63(52.1 \%)$ & $3(20.0 \%)$ \\
\hline \multicolumn{5}{|c|}{ Use rubber dam in caries filling } \\
\hline Never use & $104(45.4 \%)$ & $21(22.6 \%)$ & $80(66.1 \%)$ & $3(20.0 \%)$ \\
\hline Occasionally use & $86(37.6 \%)$ & $49(52.7 \%)$ & $30(24.8 \%)$ & $7(46.7 \%)$ \\
\hline Often use & $38(16.6 \%)$ & $23(24.7 \%)$ & $11(9.1 \%)$ & $4(26.7 \%)$ \\
\hline Always use & $1(0.4 \%)$ & $0(0.0 \%)$ & $0(0.0 \%)$ & $1(6.7 \%)$ \\
\hline \multicolumn{5}{|c|}{ Use rubber dam in root canal treatment } \\
\hline Never use & $91(39.7 \%)$ & $64(48.1 \%)$ & $13(16.9 \%)$ & $14(73.7 \%)$ \\
\hline Occasionally use & $77(33.6 \%)$ & $49(36.8 \%)$ & $23(29.9 \%)$ & $5(26.3 \%)$ \\
\hline Often use & $54(23.6 \%)$ & $18(13.5 \%)$ & $36(46.8 \%)$ & $0(0.0 \%)$ \\
\hline Always use & $7(3.1 \%)$ & $2(1.5 \%)$ & $5(6.5 \%)$ & $0(0.0 \%)$ \\
\hline \multicolumn{5}{|c|}{ Mastery degree of rubber dam usage } \\
\hline Level 0 & $32(14.0 \%)$ & $7(7.5 \%)$ & $19(15.7 \%)$ & $6(40.0 \%)$ \\
\hline Level 1 & $93(40.6 \%)$ & $28(30.1 \%)$ & $60(49.6 \%)$ & $5(33.3 \%)$ \\
\hline Level 2 & $80(34.9 \%)$ & $37(39.8 \%)$ & $39(32.2 \%)$ & $4(26.7 \%)$ \\
\hline Level 3 & $24(10.5 \%)$ & $21(22.6 \%)$ & $3(2.5 \%)$ & $0(0.0 \%)$ \\
\hline Total & 229 & 93 & 121 & 15 \\
\hline
\end{tabular}

by tooth type [8]. A survey investigated general practitioners, specialized practitioners, undergraduate final year students, and endodontists in the state of Odisha, India. The results showed that $30 \%$ have used rubber dam for root canal cases and $23 \%$ use them for all cases of root canal treatment. Rubber dam usage was $15.4 \%$ in paediatric patients and $34.4 \%$ in adult patients [5]. The prevalence of rubber dam use was only $18 \%$ in southern Nigeria. Up to $77 \%$ of the respondents had not used rubber dams or did not know how to use them [9]. Rubber dam usage rate is less than $8 \%$ in the Republic of Czech [10]. In China, the situation of rubber dam usage is also far from being good and optimistic. There are few surveys investigating rubber dam usage rate in Chinese mainland. Therefore, this study investigated 300 general practitioners 


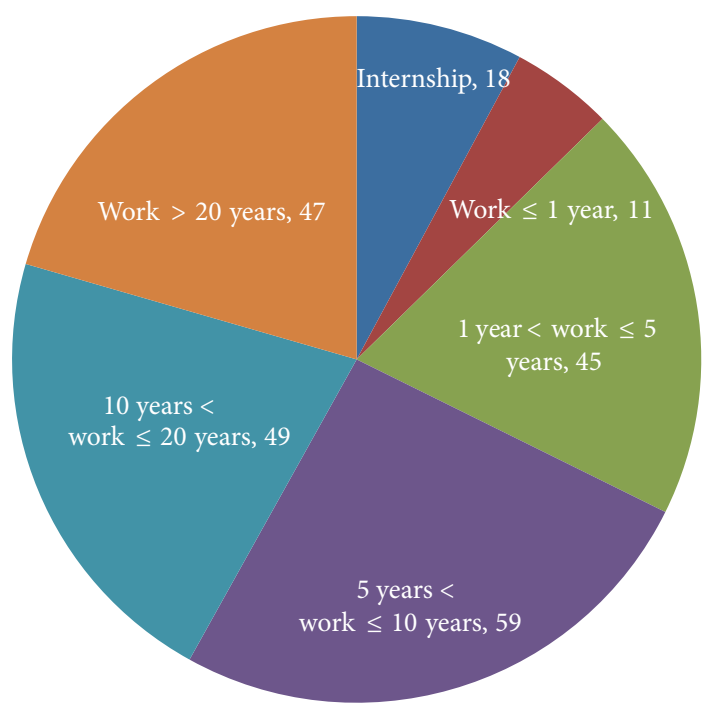

FIGURE 2: The distribution of respondents' years of working experience.

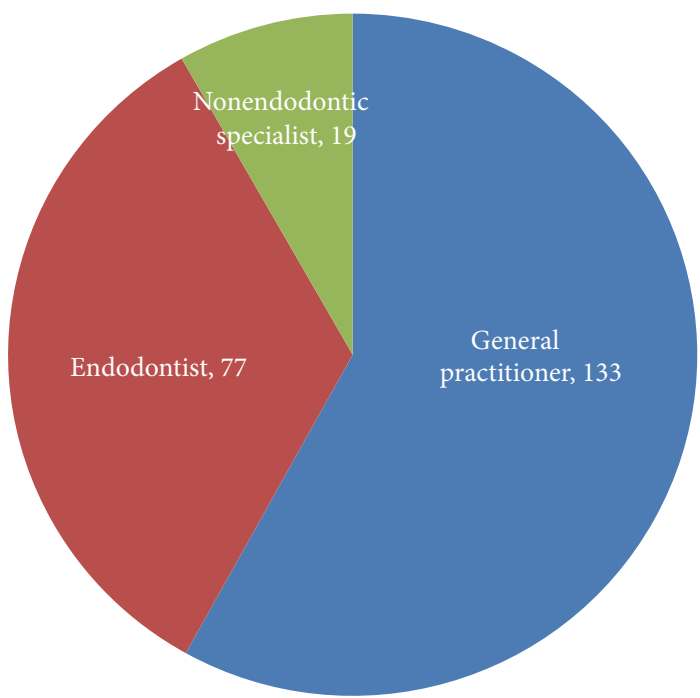

Figure 3: The field (general or specialized) distribution of respondents engaged in dentistry.

and specialists from 18 medical institutions of Tianjin city. The results showed that $63.3 \%$ of respondents used rubber dam; however, only $0.4 \%$ and $3.1 \%$ always use rubber dam in the treatment of cavity filling and root canal treatment, respectively. The overall usage of rubber dam technique is really low. Compared with the developed countries, there is still a big gap.

Several factors may influence the usage of rubber dam, such as the practitioner's gender, years of professional experience, field, type of medical institutions, costs and profits, and previous experience in using rubber dam. Unal et al. reported that gender affected the preference of intracanal medicament, periapical radiographs for working-length determination, root canal instrument, root canal sealers, and root canal

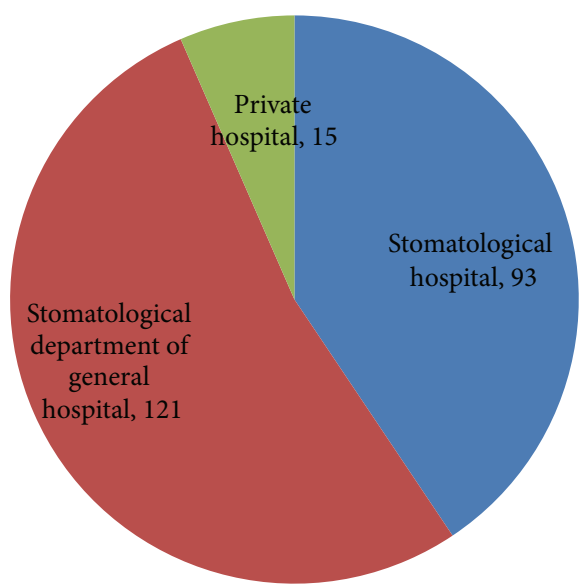

FIgURE 4: The distribution of the type of medical institutions where respondents work.

obturation technique. However, there was no statistical significance $(P>0.05)$ showing that gender affects rubber dam usage [11]. The survey carried out in India also found that there was no significant difference between males and females on rubber dam usage [12]. Our results compare well with these studies mentioned above.

Years of working experience is considered to be closely related to the usage of rubber dam technique. Savani et al. reported that general practitioners (GPs) within 10 years of experience were more likely to use rubber dam compared with those in practice for more than 20 years $(P<0.05)$. Interestingly, GPs with more than 5 hours of continuing education (CE) were more likely to use rotary instrumentation, irrigant activation devices, and apex locators and perform molar root canal therapy and retreatment but not likely to use rubber dam [6]. Gupta and Rai showed that respondents with less than 5 years of working experience use rubber dam more than those with more than 15 years of working experience. There were significant differences between these two groups [12]. This study shows that dentists who have 5 years < working experience $\leq 10$ years gain the highest rubber dam usage rate while those working more than 20 years have the lowest usage rate. Savani et al. pointed out that the more recently graduated dentists were more likely to use rubber dam. They were more likely to adopt new technologies than those who practiced for more than 20 years [6]. Anabtawi et al. showed that even the graduation year was not statistically significant in multivariable regressions when including the "type of practice" variable, and higher usage rate among newly graduates had been confirmed [1].

However, there are also opposite reports that older practitioners use rubber dam more often than their younger counter parts [13]. While in that study, the majority of practitioners did not use rubber dam during root canal therapy. Another report showed that years of working experience did not influence the preference of isolation methods [11]. Practitioners are more likely to do what they have been taught in dental school after their graduation. When they have never used rubber dam in their studying life, they tend to not try 
to use it later. Maybe that is the reason why studies showed that more experienced clinicians were resistant to use rubber dam. Furthermore, postgraduation training is also important and may influence rubber dam usage. A significantly higher proportion of respondents having postgraduate qualifications carried out root canal treatment using rubber dam, compared to those who did not have postgraduate qualifications [12]. Dentists with postgraduation training placed rubber dam more frequently [14], while endodontic practice of general dentists sometimes did not always comply with quality guidelines [4]. Several studies showed that rubber dam is used frequently for root canal treatment compared to operative treatment. In this study, data also showed low prevalence of its usage during endodontic therapy. Therefore, further emphasis should be placed on the advantages of rubber dam usage in clinical dentistry at dental school and through continuing dental education for practitioners to update their knowledge [5].

Many studies have shown that level of specialization affected dentists' rubber dam usage. Endodontists used more frequently rubber dam in restorative dentistry or root canal treatment than did nonspecialists $[1,15]$. This study showed significant differences among general practitioners, endodontists, and nonendodontic specialists in the prevalence of rubber dam usage. Rubber dam usage rate among endodontists was much higher than that of general dentists and other nonendodontists, similar to other reports in the literature.

The type of medical institutions also has certain impacts on rubber dam usage. Rubber dam usage varied significantly by geographic region and practice type [1]. Udoye and Jafarzadeh reported that dentists in the government sector used rubber dam more often than did dentists in the private sector [9]. Lin et al. found that rubber dam usage in public hospital was significantly higher than that of private dental clinics in Taiwan [16]. Practitioners in group practices used rubber dam more than those in solo practices [17]. This survey shows that the use of rubber dam in the department of stomatology of general hospital and private clinic is relatively low compared with specialized stomatological hospital. Interestingly, as shown in Table 4, although there was lower percentage (47.9\%) in general hospital group for "have used rubber dam" compared with that $(80.5 \%)$ in specialized stomatological hospital group, the percentage of "often use" plus "always use" in general hospital group in root canal treatment was much higher $(46.8 \%+6.5 \%)$ compared with that $(13.5 \%+$ $1.5 \%)$ in specialized hospital group, while specialized hospital group owned higher rubber dam usage rate in caries filling compared with other groups. It is suggested that specialtailored training should be strengthened for dentist working at different types of medical institutions.

Other factors such as ethnicity, dental insurance, and age and patient level characteristics may also influence the prevalence of rubber dam usage [18]. Therefore, although most of dentists agree that rubber dam is the standard of care in endodontic treatments, discrepancies still existed between principles and practice. Emphasis on education and increased awareness of the importance of rubber dam usage are needed. Dentists should update their knowledge and practices with current techniques and materials through continuous dental education programs [19]. The current guidelines need to be more clear and straightforward and special management should be highlighted [20].

\section{Conclusion}

The survey indicated that the prevalence of rubber dam usage in Tianjin city is still low. The practitioner's gender, years of professional working experience, general or specialized field, and the type of medical institutional settings they work for are factors that need to be considered during making policy and executing training.

\section{Competing Interests}

The authors declare that they have no conflict of interests related to this study.

\section{Acknowledgments}

The authors would like to thank Tianjin Stomatological Quality Control Committee panel who are continuously supervising and reviewing their progress.

\section{References}

[1] M. F. Anabtawi, G. H. Gilbert, M. R. Bauer et al., "Rubber dam use during root canal treatment: findings from The Dental Practice-Based Research Network," Journal of the American Dental Association, vol. 144, no. 2, pp. 179-186, 2013.

[2] M. Raoof, N. Zeini, J. Haghani, S. Sadr, and S. Mohammadalizadeh, "Preferred materials and methods employed for endodontic treatment by Iranian general practitioners," Iranian Endodontic Journal, vol. 10, no. 2, pp. 112-116, 2015.

[3] A. Kohli, S. Singh, R. Podar, S. Dadu, and G. Kulkarni, "A comparative evaluation of endodontic practice trends in India: 'the Mumbai study"' Indian Journal of Dental Research, vol. 25, no. 6, pp. 729-736, 2014.

[4] M. Neukermans, J. Vanobbergen, M. De Bruyne, M. Meire, and R. J. G. De Moor, "Endodontic performance by Flemish dentists: have they evolved?" International Endodontic Journal, vol. 48, no. 12, pp. 1112-1121, 2015.

[5] G. Shashirekha, A. Jena, A. B. Maity, and P. K. Panda, "Prevalence of rubber dam usage during endodontic procedure: a questionnaire survey," Journal of Clinical and Diagnostic Research, vol. 8, no. 6, pp. ZC01-ZC03, 2014.

[6] G. M. Savani, W. Sabbah, C. M. Sedgley, and B. Whitten, "Current trends in endodontic treatment by general dental practitioners: report of a United States national survey," Journal of Endodontics, vol. 40, no. 5, pp. 618-624, 2014.

[7] J. Goldfein, C. Speirs, M. Finkelman, and R. Amato, "Rubber dam use during post placement influences the success of root canal-treated teeth," Journal of Endodontics, vol. 39, no. 12, pp. 1481-1484, 2013.

[8] N. C. Lawson, G. H. Gilbert, E. Funkhouser, P. D. Eleazer, P. L. Benjamin, and D. C. Worley, 'General dentists' use of isolation techniques during root canal treatment: from the national dental practice-based research network," Journal of Endodontics, vol. 41, no. 8, pp. 1219-1225, 2015. 
[9] C. I. Udoye and H. Jafarzadeh, "Rubber dam use among a subpopulation of Nigerian dentists," Journal of Oral Science, vol. 52, no. 2, pp. 245-249, 2010.

[10] M. Kapitan and Z. Sustova, "The use of rubber dam among Czech dental practitioners," Acta Medica, vol. 54, no. 4, pp. 144148, 2011.

[11] G. C. Unal, B. U. Kaya, A. G. Tac, and A. D. Kececi, "Survey of attitudes, materials and methods preferred in root canal therapy by general dental practice in Turkey: part 1," European Journal of Dentistry, vol. 6, no. 4, pp. 376-384, 2012.

[12] R. Gupta and R. Rai, "The adoption of new endodontic technology by indian dental practitioners: a questionnaire survey," Journal of Clinical and Diagnostic Research, vol. 7, no. 11, pp. 2610-2614, 2013.

[13] S. M. Jenkins, S. J. Hayes, and P. M. H. Dummer, "A study of endodontic treatment carried out in dental practice within the UK," International Endodontic Journal, vol. 34, no. 1, pp. 16-22, 2001.

[14] F. F. Demarco, R. A. Baldissera, F. C. Madruga et al., "Anterior composite restorations in clinical practice: findings from a survey with general dental practitioners," Journal of Applied Oral Science, vol. 21, no. 6, pp. 497-504, 2013.

[15] G. G. Nascimento, M. B. Correa, N. Opdam, and F. F. Demarco, "Do clinical experience time and postgraduate training influence the choice of materials for posterior restorations? Results of a survey with brazilian general dentists," Brazilian Dental Journal, vol. 24, no. 6, pp. 642-646, 2013.

[16] H.-C. Lin, S.-F. Pai, Y.-Y. Hsu, C.-S. Chen, M.-L. Kuo, and S.F. Yang, "Use of rubber dams during root canal treatment in Taiwan," Journal of the Formosan Medical Association, vol. 110, no. 6, pp. 397-400, 2011.

[17] S. Koshy and N. P. Chandler, "Use of rubber dam and its association with other endodontic procedures in New Zealand," The New Zealand Dental Journal, vol. 98, no. 431, pp. 12-16, 2002.

[18] G. H. Gilbert, M. S. Litaker, D. J. Pihlstrom, C. W. Amundson, and V. V. Gordan, "Rubber dam use during routine operative dentistry procedures: findings from the dental PBRN," Operative Dentistry, vol. 35, no. 5, pp. 491-499, 2010.

[19] A. Gaikwad, D. Jain, P. Rane, S. Bhondwe, S. Taur, and S. Doshi, "Attitude of general dental practitioners toward root canal treatment procedures in India," The Journal of Contemporary Dental Practice, vol. 14, no. 3, pp. 528-531, 2013.

[20] H. M. A. Ahmed, S. Cohen, G. Lévy, L. Steier, and F. Bukiet, "Rubber dam application in endodontic practice: an update on critical educational and ethical dilemmas," Australian Dental Journal, vol. 59, no. 4, pp. 457-463, 2014. 


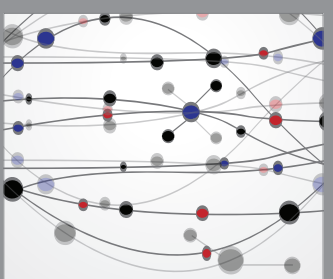

The Scientific World Journal
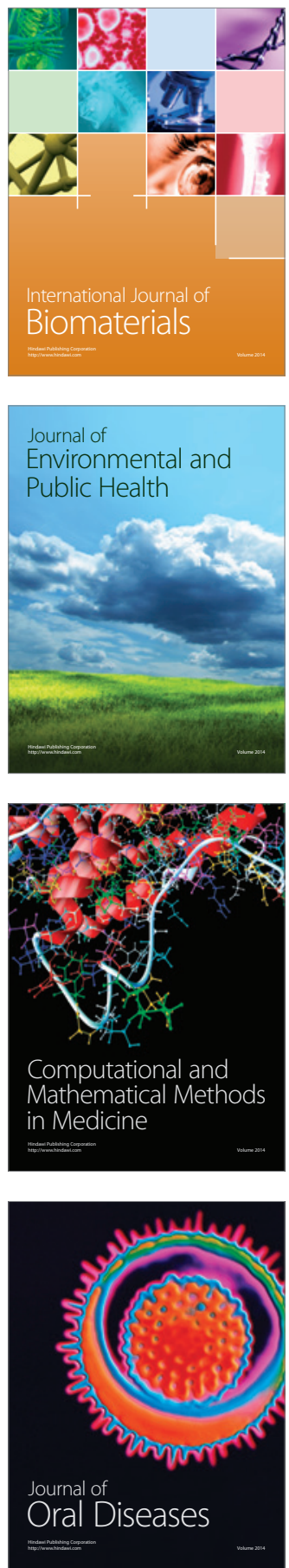
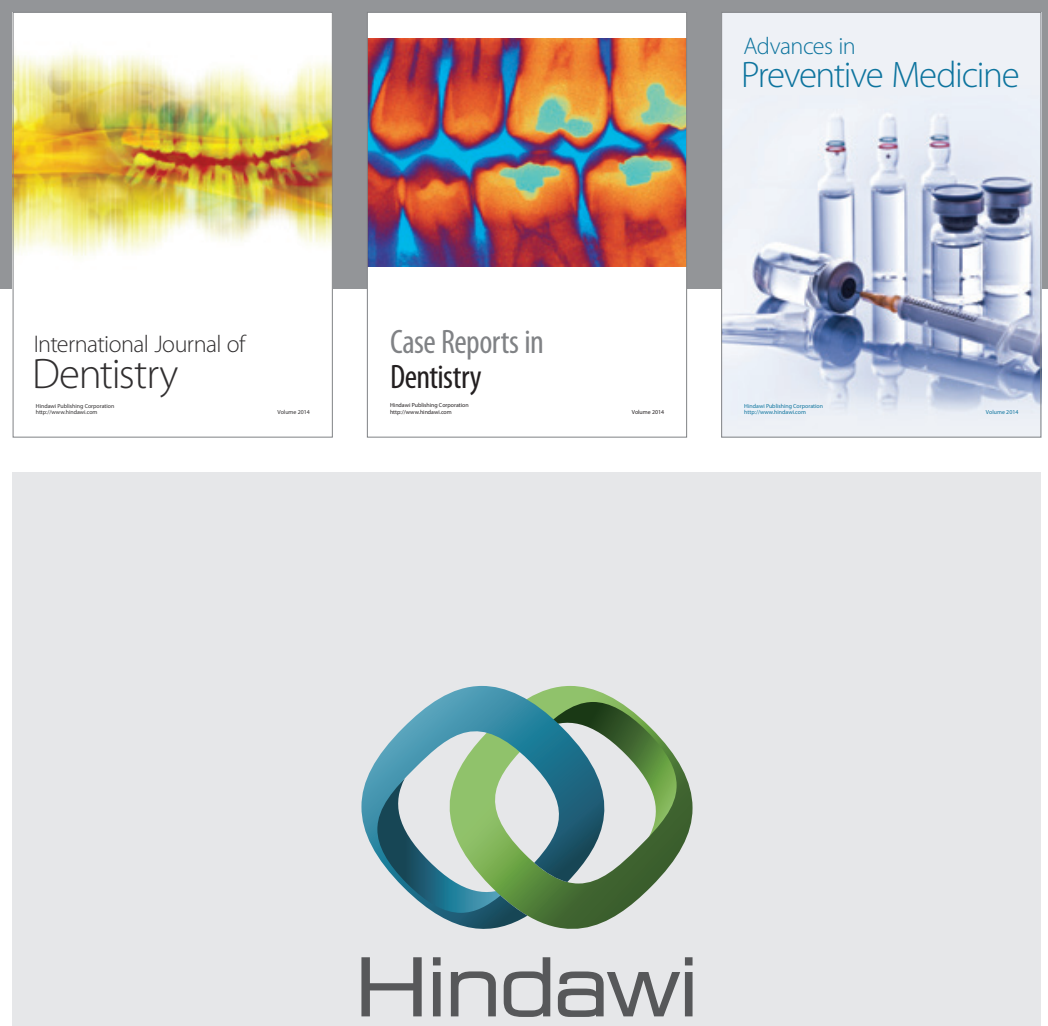

Submit your manuscripts at

http://www.hindawi.com
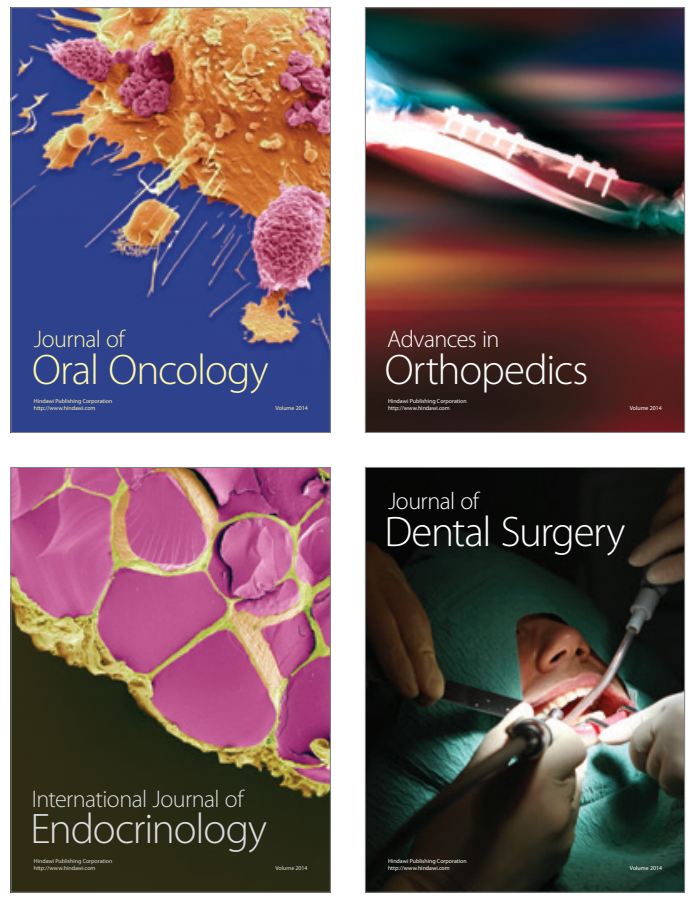
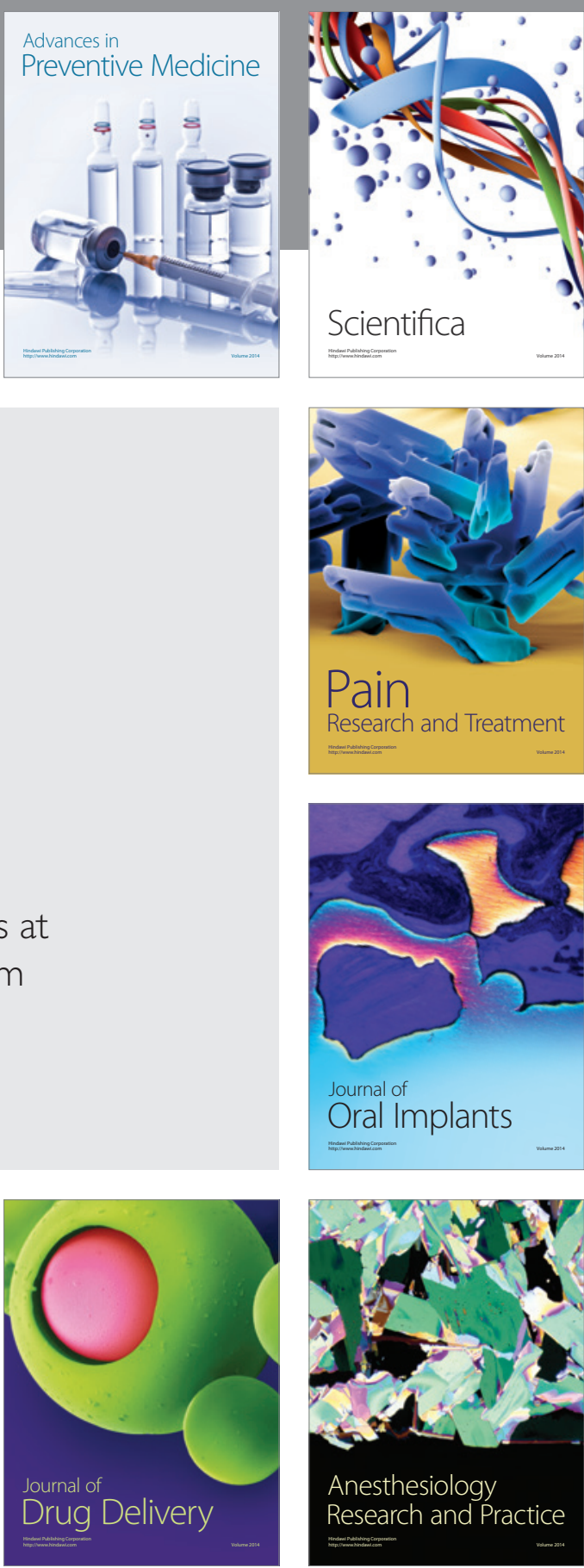

Scientifica
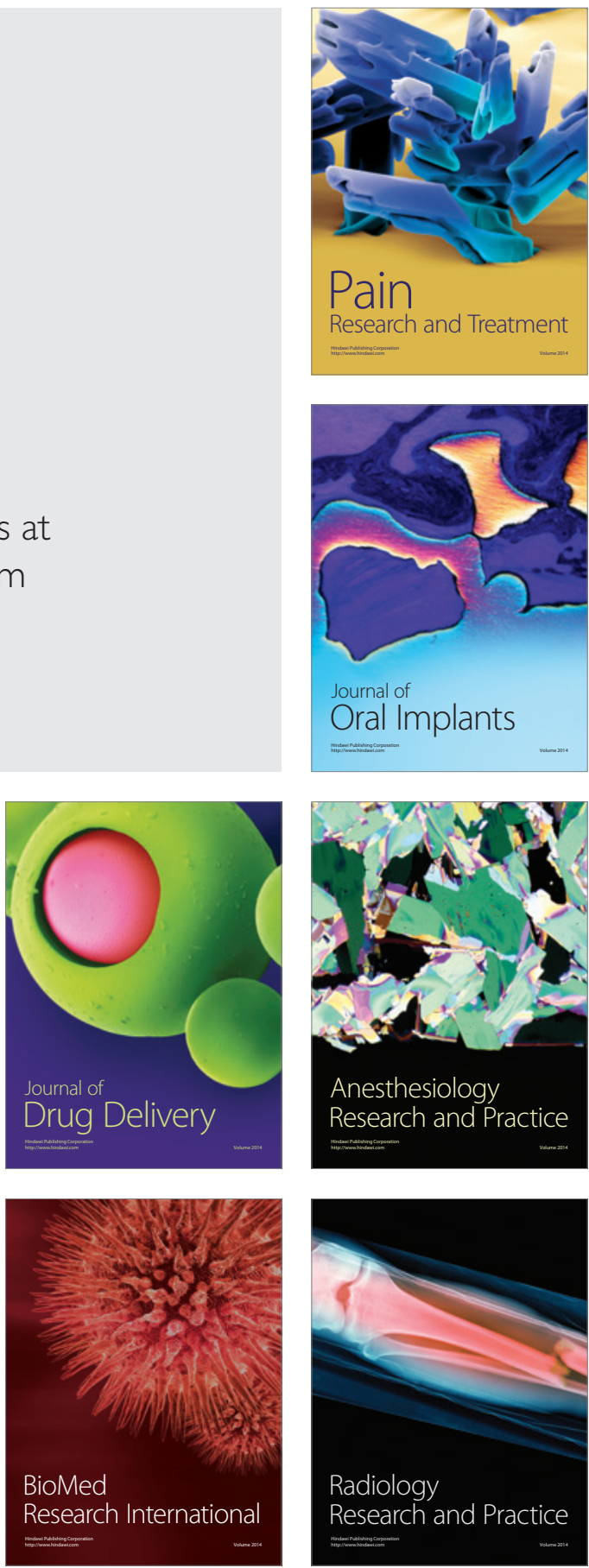